\title{
Should the use of complementary and alternative medicine be restricted?
}

\author{
Saikrishna Nadimpalli*
}

Student A2 levels

Cardiff Sixth Form College,

1 and 3 Trinity Court,

21-27 Newport Road,

Cardiff-CF24 0 AA

United Kingdom

Received: 07 September 2016

Accepted: 12 September 2016

*Correspondence to:

Saikrishna Nadimpalli,

Email: skrishna.nadimpalli@ gmail.com

Copyright: (C) the author(s), publisher and licensee Medip Academy. This is an openaccess article distributed under the terms of the Creative Commons Attribution NonCommercial License, which permits unrestricted noncommercial use, distribution, and reproduction in any medium, provided the original work is properly cited.

\begin{abstract}
There is a considerable amount of doubt about the effectiveness and safety profile of complementary and alternative medicine (CAM). This review article aimed at observing the trend of use of CAM in various countries and its acceptability. It was observed that CAM was more commonly used as a form of treatment in developing countries when compared to the developed countries which may be due to the cultural and economic aspects. The major reason for restricted use of CAM in developed countries is the lack of scientific evidence and adequate studies confirming its efficacy and safety. It involves use of several natural products and body parts of animals which might not always be beneficial and cause harm not only to individual but also the environment. However, some treatments like artemisin for malaria are considered the treatment of choice. CAM is an extensive field consisting of numerous wide ranging therapies, differing in concepts and effectiveness; hence, it is very difficult to have a generalised approach while drawing conclusions about its usage. It is important that more studies are conducted comparing CAM with western medicine for scientific input on its efficacy and safety. Proper monitoring and education about CAM like Ayurveda and yoga by qualified personnel can avoid any harm and facilitate its use as a complementary treatment to western medicine, combination of these two can form a more holistic medical model for treatment.
\end{abstract}

Keywords: Complementary and alternative medicine, Western medicine, Developing countries, Developed countries

\section{INTRODUCTION}

The importance of medicine in today's day and age cannot be overstated. New elements are incorporated into this field at a rapid pace, leading to a range of diverse healing techniques and treatments being formed. Diagnosis, drugs, and surgeries are key features of western medicine and are predominantly the main form of treatment offered by hospitals around the world. However, there are other unconventional forms of healing included in Complementary and Alternative Medicine (CAM). The World Health Organization defines CAM as "a broad set of health care practices that are not part of a country's own tradition and are not integrated into the dominant health care system". ${ }^{1-3}$
Today, CAM is subjected to burning questions regarding its effectiveness and whether it does more harm than good. In this essay, I will discuss the answers to these questions by analysing the current state of affairs over the usage of CAM.

\section{Prevalence of use of CAM}

Around the world, the percentages of people using the various forms of CAM are diverse. As estimated by the WHO, $40 \%$ of the population of China is dependent on Traditional Chinese Medicine (TCM) as their primary form of healthcare. ${ }^{4}$ In Africa, a significant $80 \%$ of the population is dependent on CAM. ${ }^{5}$ In 2008, a survey found that $38 \%$ of adults in America use such treatments. ${ }^{6}$ Furthermore, it was found that one eighth of the British population has used CAM. ${ }^{7}$ It is important to 
note that the studies which obtained these figures took place in different years and hence the percentages may not accurately represent current trends. Nevertheless, they surely do give a general idea of the number of people dependant on CAM. It can be seen that a larger percentage of people from developing countries use CAM. One reason for this could be that many developing countries in Asia and Africa have their own forms of traditional medicine, which have been rooted into their culture for ages. Also, people from developing countries usually have a lower standard of living compared to people from western countries, causing them to rely on cheap CAM treatments instead of western medicine. Furthermore, another factor which could attract people into using CAM treatments is that they are minimally invasive and this could be preferable for people from cultures where undergoing surgeries and taking chemical drugs is opposed. Hence, this creates a bias the population to use such treatments as their primary form of healthcare.

\section{Challenges and limitations of use of CAM}

In a survey done by the Royal College of Physicians (RCP) in UK, it was found that one-third of the 3000 responders practised $\mathrm{CAM}^{8}$ The data shows that a significant proportion of practitioners are involved in practising CAM. Yet, in the United Kingdom, the availability of CAM treatments on the National Health Service (NHS) is limited. Some treatments like acupuncture, acupressure and the Alexander technique are offered in a few cases. ${ }^{9}$ One could argue that the NHS not offering many CAM treatments limits the freedom of choice over what form of treatment a person would like to receive. However, running on a fixed budget could be the reason for this. Incorporating more CAM treatments could make the NHS marginalise other treatments or even possibly bring economic burdens. Furthermore, the fact that CAM treatments are normally less scientifically backed as compared to western medicine, cannot be ignored. Being scientific renders a treatment to have support of observable and measurable variables, enabling one to have more confidence in the effectiveness of a treatment. Also from an ethical perspective, it may be argued that it is vital that hospitals provide a patient with a form of treatment that will have the best results. Therefore, the NHS's decision may be justified by saying that it is more beneficial to offer a smaller number of scientifically backed medical treatments, than take a risk of providing a large number of treatments which may include some less effective treatments.

Traditional Chinese Medicine (TCM), Ayurveda and Naturopathy are a few CAM treatments which heavily incorporate the use of natural ingredients, and this factor is often used as a "selling-point" for these treatments. However, using natural ingredients may not always beneficial. In USA, the Food and Drug Administration (FDA) has banned a plethora of herbal medicines for causing adverse effects. ${ }^{10}$ The TCM herb ephedra, which was alleged to be an energy and weight-loss product was banned because it was linked to causing irregular heart rhythms and heart attacks in an animal study. ${ }^{11}$ Furthermore, some TCM concoctions are made from the body parts of animals like bears, tigers and crocodiles. It was found that the demand for animal parts in TCM has given impetus to poaching, not only in China, but also in other parts of the world, like South Africa, where the number of Rhinos being killed for their horns is drastically rising. ${ }^{12}$ The harsh opposition to this has led to campaigns like "Save the Rhino". On the basis of these factors, it may be argued that such CAM treatments cause harm not only to the person using the treatment, but also the environment and hence restricting them may be favoured.

\section{Advantages of CAM}

Nevertheless, TCM has had its fair share of praise and support. Tu Youyou, a TCM pharmaceutical chemist, discovered the Chinese herb artemisinin, which is now used to treat malaria and has been pivotal in saving the lives of millions of people. This led her to win the Nobel Prize for Medicine in 2015. ${ }^{13}$ Winning the Nobel prize, a highly prestigious honour, shows the importance of Youyou's research and reflects on how some aspects of TCM can be greatly beneficial. Furthermore, TCM is also praised for its approach to treating illnesses. While western medicine aims to only treat the symptoms of a disease, TCM aims to find the underlying cause. Hence this makes people aware of the reason why they contracted the disease in the first place. This could be considered to be a better long term solution as it reduces the likelihood of contracting the same disease again. Overall, although there are some areas of TCM which have been criticized, there are also some factors which have had heavily positive social implications, making it ambiguous as to whether such practices must be restricted or not.

\section{CAM in India}

While some countries like America restrict certain aspects of CAM, there are others like India which encourages them. In 2014, the Indian government established the ministry of "AAYUSH" to promote practices like Ayurveda and Yoga. ${ }^{14}$ Ayurveda is an ancient Indian, traditional CAM practice, which has been suggested to be useful in helping deal with an array of health conditions. It was found that Ayurveda was helpful in dealing with Osteoarthritis, enabling us to be more confident in the effectiveness of Ayurveda; however, its use must be carefully monitored, because just like TCM, some Ayurvedic medicines may be harmful and cause adverse effects. ${ }^{15}$ The Prime Minister of India, Mr. Modi, emphasised on the importance of Indian CAM and further suggested having an International Yoga Day. ${ }^{16} \mathrm{~A}$ metaanalysis found Yoga to be effective in the reduction of depression and in the promotion of well-being. ${ }^{17}$ Many other studies have shown Yoga to be beneficial in dealing 
with various issues. Today, Yoga has become a vastly followed CAM practice, with yoga institutes and studios being established all over the world. Nevertheless, the commercialisation of Yoga has resulted in many unqualified Yoga practitioners. ${ }^{18}$ This could result in people undergoing mediocre training which would consequentially cause injuries and hence waste their money. People with such experiences have filed lawsuits against Yoga studios for issues of negligence. ${ }^{18}$ Regardless, this issue does not undermine the effectiveness of Yoga when it is taught by people who are properly trained. Hence, it may be argued that the practice of Yoga must not be restricted, but instead the Yoga trainers must be inspected to check if they have the proper qualifications.

A point that is often used to support the restriction of CAM treatments is that some of them like Homeopathy and Reiki are argued to "work' only because of the placebo effect. According to a study by Professor Paul Glasziou, Homeopathy did not help deal with any of the 68 illnesses. Furthermore, he described Homeopathy to be a "therapeutic dead-end". ${ }^{19}$ We can be confident in Glasziou's work, because along with him being a leading scientist and a former chairperson of a research institute, almost 1800 other studies have had similar findings showing homeopathy to be ineffective. ${ }^{20}$ Peter Chappell, a renowned homeopath, famously claimed that he could reverse AIDS by using Homeopathic medicines. He runs the Amma Resonance Healing Foundation (ARHF) in Ethiopia, to 'treat' patients with AIDS. ${ }^{21}$ Chappell is also selling Homeopathic medicines for problems from bed wetting to malaria. His work has sparked open letters to WHO Africa to restrict such practices. ${ }^{22}$ Yet, ever since Chappell created ARHF, many other similar organizations have been established in different parts of Africa. In Kenya, the Abha Light Foundation has 25 mobile clinics, 20 health centres and 5 AIDS clinics which sell Homeopathic medicines to treat illnesses. ${ }^{21}$ In favour of Homeopathic treatments, it may be argued that although these practices do not cause any improvement, they rarely cause any physical harm which makes them seem less dangerous. Nevertheless, a person may undergo psychological harm from facing disappointment after not seeing any improvement in his/her health after spending money on such treatments. Hence from an ethical standpoint, it could be contended that, the use of such placebo treatments must be restricted.

\section{CONCLUSION}

While a lot of studies have been done to show whether CAM treatments are effective or not, little is known about the biological and psychological reasons for why treatments like faith healing or Reiki are suggested to work. Knowing this will help make better judgements on whether or not the treatments may have potential long term risks or whether they are effective in the first place. Furthermore, western medicine has been tested vigorously through methods like drug trials and it would be fair to say that much more funded research has been done into it compared to CAM. It is essential to have more studies done on the efficacy of some CAM treatments, so that they can be efficiently compared with the western medical model. Hence more objective and quantitative research on CAM is definitely needed.

Before I started my research I believed that banning CAM treatments would be beneficial as it would make everyone use western medicine, an option I would personally consider to be safer. Now, after thorough research, I believe that banning all CAM therapies wouldn't be fair, because there are some CAM therapies which have been shown to be genuinely effective. As CAM is an extensive field consisting of numerous wide ranging therapies, differing in concepts and effectiveness, it is very difficult to have a generalist approach while drawing conclusions about the usage of it. Nevertheless, I would like to conclude by saying that the use of CAM treatments must not be restricted, but instead, health organizations around the world must educate people about the uses of different CAM treatments and where they are legitimately effective. Also, CAM treatments could be promoted as a complement and not an alternative to western medicine and there could be a combination of these two to form a more holistic medical model. Finally, it is important to consider that we live in a society where the influence of science is continually growing. From a 'survival of the fittest' view, I would like to think that the ineffective CAM treatments would cease to exist in the next few decades, as they would be overpowered by more effective and robust alternatives.

\section{Funding: No funding sources \\ Conflict of interest: None declared \\ Ethical approval: Not required}

\section{REFERENCES}

1. McCarthy PW, Langweiler MJ, eds. Methodologies for effectively assessing complementary and alternative medicine (CAM): research tools and techniques. J Clin Res Best Pract. London: Jessica Kingsley publishers; 2015.

2. Heller T, Lee-Treweek G, Katz J, Stone J, Spurr S, editors. Perspectives on complementary and alternative medicine. United Kingdom: The Open University; 2005.

3. Qi Z. Traditional medicine: Definitions. WHO; Geneva. Available at: http://www.who.int/medicines/areas/traditional/defin itions/en/. Accessed 25 August, 2016.

4. Traditional medicine report by The Secretariat. World Health Organization; Geneva 2003. Available at:

http://apps.who.int/iris/bitstream/10665/78244/1/ea5 618.pdf. Accessed 25 August, 2016.

5. WHO Traditional Medicine Strategy 2002-2005. World Health Organization; Geneva 2002. Available at: 
http://www.wpro.who.int/health_technology/book_ who_traditional_medicine_strategy_2002_2005.pdf. Accessed 25 August, 2016.

6. The use of complementary and alternative medicine in the United States. National Center for Complementary and Integrative Health (NCCIH); USA 2008. Available at: https://nccih.nih.gov/research/statistics/2007/camsur vey_fs1.htm. Accessed 25 August, 2016.

7. Shankar PR. Essential medicines and health products information portal. J Pharmacol Pharmacother 2014;5:74-5.

8. Report: Can Alternative Medicine Be Integrated into Mainstream Care? National Center for Complementary and Integrative Health (NCCIH); USA 2001. Available at: https://nccih.nih.gov/news/events/012301. Accessed 25 August, 2016.

9. Complementary and alternative medicine. NHS choices. Available at: http://www.nhs.uk/Livewell/complementaryalternative-medicine/Pages/complementaryalternative-medicines.aspx. Accessed 25 August, 2016.

10. RM. FDA Issues final rule banning ephedra. Herbal Gram. J Am Botanical Council. 2004;62:63-7.

11. Adamson PB, Suarez J, Ellis E, Kanaly T, Vanoli E. Ephedrine increases ventricular arrhythmias in conscious dogs after myocardial infarction. J Am College Cardiol. 2004;44(8):1675-8.

12. Conca J. Extinction by traditional Chinese medicine - an environmental disaster. Forbes 2014. Available at:http://www.forbes.com/sites/jamesconca/2014/08/ 08/extinction-by-traditional-chinese-medicine-anenvironmental-disaster/\#26df8bcd39fc. Accessed 25 August, 2016.

13. Halton $\mathrm{C}$. Nobel Prize winner Tu Youyou helped by ancient Chinese remedy. BBC News 2015 Oct 6; Sect. China blog. Available at http://www.bbc.com/news/blogs-china-blog34451386. Accessed 25 August, 2016.

14. PM Modi creates AAYUSH ministry for focus on yoga, Ayurveda. First Post 2014 Nov 10; Sect. India. Available at http://www.firstpost.com/india/pmmodi-creates-aayush-ministry-focus-yoga-ayurveda1796275.html. Accessed 25 August, 2016.

15. Chopra A, Saluja M, Tillu G, Sarmukkaddam S, Venugopalan A, Narsimulu G, et al. Ayurvedic medicine offers a good alternative to glucosamine and celecoxib in the treatment of symptomatic knee osteoarthritis: a randomized, double-blind, controlled equivalence drug trial. Rheumatol (Oxford). 2013;52(8):1408-17.

16. Kalra A. PM Narendra Modi turns yoga, ayurveda dream into ministry. Business today in 2014 Nov 11; Sect. Economics and politics. Available at http://www.businesstoday.in/current/economypolitics/narendra-modi-shapes-yoga-ayurvedadreams-into-ministry/story/212233.html. Accessed 25 August, 2016.

17. Knobben S. A meta-analysis of the effectiveness of yoga on mental health; taking on a dual perspective reflecting the medical and positive perspective of mental health [dissertation]. Enschede: University of Twente; 2013. Available at http://essay.utwente.nl/63524/1/Knobben,_S.__s1135902_(verslag).pdf. Accessed 25 August, 2016.

18. Lawrence SJ. Yoga's growing threat of legal liability. Counterpunch 2014 July 4. Available at http://www.counterpunch.org/2014/07/04/yogasgrowing-threat-of-legal-liability/. Accessed 25 August, 2016.

19. Fenton S. Homeopathy effective for 0 out of 68 illnesses, study finds. Independent 2016 Feb 19; Sect. Health and Families. Available at http://timesofindia.indiatimes.com/home/science/Ho meopathy-found-to-be-effective-for-0-out-of-68illnesses/articleshow/51066514.cms. Accessed 25 August, 2016.

20. Blakemore E. 1, 800 Studies Later, Scientists Conclude Homeopathy Doesn't Work. Smithsonian Magazine 2015 Mar 11; Sect. Smart news. Available at http://www.smithsonianmag.com/smartnews/1800-studies-later-scientists-concludehomeopathy-doesnt-work-180954534/. Accessed 25 August, 2016.

21. AIDS: more homeopathic killing. 2007. Available at: http://www.dcscience.net/2007/12/01/aids-morehomeopathic-killing/. Accessed 25 August, 2016.

22. Wilson J, Baker M, Ball H, Pinheiro VB, Bristo J, Casey D. Homeopathy and serious diseases in the developing world: an open letter from early career medics and researchers. London 2009. Available at: http://www.homeowatch.org/news/who_letter.html. Accessed 25 August, 2016.

Cite this article as: Nadimpalli S. Should the use of complementary and alternative medicine be restricted? Int J Basic Clin Pharmacol 2016;5:16914. 